${ }^{1}$ Gatot Supangkat Samidjo, ${ }^{2}$ Sutrisno Wibowo, ${ }^{3}$ Sutrisno

1Prodi A groteknologi, Fakultas

Pertanian, U niversitas M uhammadiyah

Yogyakarta; ${ }^{2}$ Prodi M anajemen,

Fakultas E konomi dan Bisnis, U niversi-

tas M uhammadiyah Yogyakarta

3Prodi A grinisnis, Fakultas Pertanian,

U niversitas M uhammadiyah Yogyakarta

Jalan Brawijaya, Tamantirto, K asihan,

Bantul, Yogyakarta 55163

Email: supangkat@umy.ac.id

\section{Pengembangan Desa Wisata} Belajar Berbasis Potensi Alam dan Pertanian di Polengan, Srumbung, \section{Magelang}

https:/ / doi.org/ 10.18196/ bdr.415

\begin{abstract}
ABSTRAK
Untuk meningkatkan daya tarik desa sebagai tujuan wisata perlu upaya kreatif agar berbeda dengan yang lain dan lebih kompetitif, yakni perlu diarahkan menjadi Desa Belajar Berbasis Potensi Alam dan Pertanian. Tujuan pemberdayaan masyarakat ini yakni inisiasi pembangunan Desa Belajar Berbasis Potensi Alam dan Pertanian di Desa Polengan. M etode yang digunakan untuk mencapai tujuan yang ditetapkan, meliputi ceramah, diskusi, pelatihan dan praktik dengan pendekatan permasalahan dan solusi berbasis masyarakat (Participatory Rural Appraisal/ PRA). Metode PRA merupakan suatu teknik untuk menyusun dan mengembangkan program yang operasional dalam pembangunan tingkat desa. Metode PRA diterapkan dengan tujuan mampu mengungkap secara jelas keinginan masyarakat, memobilisasi sumberdaya lokal guna peningkatan produktivitas, pendapatan masyarakat, stabilisasi dan pelestarian sumberdaya lokal (Daniel, dkk, 2008). Proses pengungkapan potensi dan keinginan dilakukan melalui forum diskusi baik individual maupun kelompok atau Focus Group Discussion/FGD.Hasil yang dicapai program pemberdayaan masyarakat yang telah dilakukan di Desa Polengan, Kecamatan Srumbung, Kabupaten Magelang diapresiasi dengan baik oleh masyarakat melalui "Inisiasi Desa Belajar Alam dan Pertanian". Keberlanjutan pembangunan Desa Belajar Alam dan Pertanian diperlukan pendampingan intensif pada program pemberdayaan masyarakat lanjutan.
\end{abstract}

Kata Kunci: Desa, Wisata Belajar, Potensi Alam, Pertanian, Polengan

\title{
PENDAHULUAN
}

D esa memiliki karakter unik dan variatif yang tidak sama wilayah satu dengan lainnya baik aspek sosial, ekonomi, budaya dan lingkungannya. Karakter yang unik dan spesifik itu menjadikan desa dapat dikembangkan sesuai dengan potensinya.

Pedesaan atau kampung memiliki peluang yang besar jika dikembangkan menjadi obyek wisata, karena menjanjikan brand image yang beda. D imasa yang akan datang branding wisata akan lebih komplek, setelah branding tempat menjadi mudah tergantikan dan sulit dibedakan (Pike, 2005). Pengembangan wisata pedesaan (rural turism) sudah sejak lama menjadi topik kajian termasuk di Amerika (Gartner, 2004) 


\section{5}

Kampung W isata harus didesain mengarah pada sustainable tourism sehingga itu perlu direncanakan sebaik-baiknya dengan melibatkan masyarakat. M enurut Lansing dan De Vries (2007) Kampung W isata adalah konsep pariwisata berkelanjutan (sustainable tourism). Konsep ini diklaim sebagai konsep baru yang mampu mengatasi persoalan pengemban gan wisata secara konvensional. A da tiga hal penting dalam konsep Kampung W isata, pertama pemanfaatan sumber daya lingkungan secara optimal dengan menjaga proses-proses ekologi utama dan memelihara warisan alam serta biodiversitasnya; kedua menghargai aspek sosial budaya masyarakat asli dan wisatawan dan ketiga dalam jangka panjang menjamin kemudahan penyediaan manfaat sosial ekonomi bagi masyarakat (Welford dan Yttrhus, 2004; Lansing dan De Vries, 2007). W isata berbasis pedesaan sesuai dengan konsep community base tourism yang juga merupakan salah satu model sustainable tourism menurut Blackstok (2005).

Tourism adalah kegiatan besar dan bersifat global, sehingga mendesak diperlukan perencanaan yang spesifik. Perencana harus mengumpulkan banyak pengalaman dalam pendekatan metode perencanaan. Penelitian yang berkelanjutan dan percobaan dibutuhkan khususnya untuk menentukan bentuk optimum dari pengembangan yang dilakukan (Inskeep, 1988). Perencanaan tourismjuga bisa dilakukan dengan pendekatan 4 A yaitu : attractions, actors, actions dan atmospheres (Echtner, 2002).

D esa Polengan berbatasan dengan $D$ esa N gargosoka di sebelah Timur, Desa Tegalrandu, D esa Pandanretno, dan D esa Pucanganom di sebelah U tara, D esa Bringin di sebelah Barat, serta Desa M ranggen di sebalah Selatan.D esa Polengan membawahi tujuh dusun yaitu Polengan, Kronggahan, G ejayan, Babadan, Larangan, Lembar, dan Gowok. Desa Polengan memiliki luas wilayah kurang lebih $4 \mathrm{~km}^{2}$, dengan $60 \%$ lebih merupakan lahan pertanian. Komoditas pertanian yang dihasilkan dari wilayah adalah padi, sayur mayur seperti cabe, tomat, kubis, sawi, dan kacang panjang. Saat ini berkembang pesat budidaya salak pondoh, salak lumut serta perikanan .

D esa Polengan terletak di sisi selatan-barat daya Gunung M erapi. Pada saat erupsi Gunungapi Merapi tahun 2010, sebagian besar wilayah Desa Polengan mengalami kerusakan fisik terutama areal pertanian dan perikanan yang merupakan sumber matapencaharian utama masyarakat. W ilayah ini banyak mendapatkan perhatian dan bantuan dari berbagai lembaga termasuk dari M uhammadiyah (M uhammadiyah D isaster M anajemen C enter/ M D M C, M ajelis Lingkungan H idup/ M LH dan M ajelisPemberdayaan M asyarakat/ M PM ). Program tanggap darurat dan pemulihan (recovery) yang dilakukan oleh M D M C disambut baik oleh masyarakat Polengan dengan program D esa Tangguh 
Bencana dan kemudian dikuatkan oleh MLH dengan program pemulihan lahan, usahatani sayuran dan pertanaman salak serta pemberdayaan ekonomi oleh MPM . Pemberdayaan selanjutnya dilakukan oleh U niversitas M uhammadiyah Yogyakarta (U M Y) melalui program Kuliah Kerja $N$ yata (KKN) dengan program tindak lanjut dan penguatan program yang telah dirintis oleh MDMC, MLH dan MPM.

Potensi yang terungkap dari hasil pendampingan di atas, yakni pengembangan pangan olahan berbahan baku singkong (ketela pohon) yang dikenal dengan Patilo. Sisi lain yang terungkap yaitu bergairahnya kembali kegiatan pertanian (usahatani) sayuran melalui pendampingan tata irigasi dan rehabilitasi lahan. Keberadaan pertanaman salak baik di tegal maupun pekarangan rumah yang telah segar kembali akibat erupsi Gunungapi M erapi menambah kekayaan potensial Desa Polengan. Potensi pertanian yang dimiliki oleh D esa Polengan semakin kaya potensi dengan dukungan potensi lingkungan alamnya yang indah, mengingat letaknya tepat di lereng $G$ unungapi M erapi.

Berdasarkan potensi yang dimiliki oleh D esa Polengan maka layak apabila ditata dan dikembangkan sedemkian rupa dengan memasukkan unsur edukasi sehingga terbangun menjadi Desa W isata Belajar berbasis Pertanian dan Potensi Alam. Oleh karena itu, tujuan pengabdian pada masyarakat yan g dilakukan yaitu: 1) meningkatkan pengetahuan, wawasan dan kesadaran masyarakat akan potensi yang dimiliki oleh wilayahnya; 2) meningkatkan pengetahuan dan ketrampilan dalam pengembangan pertanian ramah lingkungan.

\section{METODE PELAKSANAAN}

M etode yang digunakan untuk mencapai tujuan yang ditetapkan, meliputi ceramah, diskusi, pelatihan dan praktik dengan pendekatan permasalahan dan solusi berbasis masyarakat (Participatory Rural A ppraisal/ PRA). M etode PRA merupakan suatu teknik untuk menyusun dan mengembangkan program yang operasional dalam pembangunan tingkat desa. M etode PRA diterapkan dengan tujuan mampu mengungkap secara jelas keinginan masyarakat, memobilisasi sumberdaya lokal guna peningkatan produktivitas, pendapatan masyarakat, stabilisasi dan pelestarian sumberdaya lokal (Daniel, dkk, 2008). Proses pengungkapan potensi dan keinginan dilakukan melalui forum diskusi baik individual maupun kelompok atau Focus G roup D iscussion/ FGD (Samidjo, 2016).

M etode yang diterapkan dalam kegiatan ini terdiri atas beberapa tahapan, yaitu sosialisasi, diskusi, identifikasi potensi ekonomi, sosial, budaya dan potensi alam lokal yang dapat dieksplorasi. Tahapan selanjutnya dilakukan pelatihan dan praktik yang terkait 


\section{7}

dengan teknologi budidaya tanaman. Sasaran yang dituju atau terlibat dalam kegiatan pengabdian pada masyarakat ini, yaitu kelompok pengrajin olahan singkong (Patilo), kelompok tani dan ternak, tokoh formal dan non formal, pemuda dan pelajar serta kelompok ibu-ibu.

\section{HASIL DAN PEMBAHASAN}

Sosialisasi

U ntuk menggali keinginan masyarakat dan penjelasan maksud serta tujuan program maka dilakukan sosialisasi yang terdiri atastiga tahapan. Tahap pertama dilakukan kepada perangkat desa Polengan, kemudian dilanjutkan diskusi di kediaman Kepala D esa. Tahap ke-3 dilakukan diskusi antara masyarakat dengan pelaksana pen gabdian pada masyarakat, termasuk mahasiswa sebagai pen damping masyarakat dalam bentuk kegiatan Kuliah Kerja $N$ yata (KKN).

H asil sosialisasi dengan tahap pertama dan kedua, sebagai berikut:

a. Bahwa masyarakat sepakat jika D esa Polengan akan diarahkan menjadi D esa W isata, namun jangan menggunakan istilah desa wisata karena sudah terlalu umum. Istilah yang digunakan adalah D esa Belajar A lam dan Pertanian. M aksudnya, jikaingin belajar tentang alam dan pertanian maka datanglah ke D esa Polengan;

b. Pusat dari kegiatan Desa Belajar adalah Dusun Gowok yang disinergikan dengan berbagai potensi di dusun lain terutama Dusun Polengan yang sudah memroduksi pangan olahan Patilo sebagai oleh-oleh khas;

c. Untuk tahap awal potensi yang akan digarap yaitu lahan atau kebun (hibah dari Kepala D esa) seluas $2000 \mathrm{~m} 2$ yang akan ditanami berbagai sayuran dan buah-buahan khususnya jambu;

d. Kelompok tani dan ternak diminta untuk mempersiapkan pengadaan pupuk kandang (kompos yang baik) hasil fermentasi, karena potensinya melimpah;

U ntuk hasil sosialisasi tahap ketiga yang melibatkan mahasiswa disepakati dua kategori program, yaitu Program Pokok dan Bantu. Program pokok, diarahkan pada persiapan menuju D esa Belajar A lam dan Pertanian, meliputi:

1. Program Gemar Belajar dan M embaca;

2. Program Pembuatan Pupuk O rganik (padat dan cair) dari limbah peternakan sapi;

3. Program kebersihan dan pengelolaan sampah;

4. Program belajar alam dan pertanian;

5. Program pelatihan industri kreatif untuk kuliner; 


\section{Program Tanaman 0 bat Keluarga.}

Selanjutnya, untuk program bantu dirancang untuk memeriahkan kegiatan keagamaan dan mendorong kebiasaan masyarakat untuk hidup bersih dan sehat. Adapun kegiatan yang disepakati dalam program bantu, antara lain G rebek Ramadhan, Pengajaran dan Lomba-omba TPA dan Gerakan Kebersihan (Jum'at Bersih).

\section{Identifikasi Potensi Alam dan Pertanian}

Hasil identifikasi potensi alam dan pertanian yang layak dijual dalam konsep wisata Polengan Desa Belajar Alam dan Pertanian, sebagai berikut:

1. Hamparan Kebun Salak Pondoh, hampir setiap rumah tangga di Desa Polengan memiliki kebun salak pondoh. Bahkan tidak hanya di tegal saja, salak pondoh juga ditanam di pekarangan sekitar rumah tinggal. Luas kepemilikan kebun salak pondoh bervariasi antara $100 \mathrm{~m}$ sd 1 ha, bahkan beberapa orang memiliki lebih dari 1 ha. Potensi yang layak jual yakni hasil panen salak pondoh dan belajar berkebun salak;

2. Potensi landskap yang indah

D esa Polengan letaknya di lereng Gunungapi M erapi dan memiliki topografi bervariasi sehingga menampilkan pan orama peman dangan alam yang indah dan asri. Jalan-jalan yang sudah beraspal dan halus di tengah hamparan sawah dan kebun salak menjadi wahana menarik untuk dijadikan ajang jalan kaki, bersepeda atau naik delman;

3. Potensi Kebun Jambu (hibah dari Kepala Desa) dan lahan kosong yang bisa dimanfaatkan sebagai arena belajar alam dan pertanian. Lahan yang tersedia seluas $2000 \mathrm{~m} 2$. Area ini dapat digunakan sebagai tempat belajar pertanian, terutama komoditas jambu, baik teknik budidayanya, olahan maupun usahataninya;

4. Potensi Kolam Renang air alami. Kolam renang ini milik Kepala D esa, berada di areal lahan sekitar $5000 \mathrm{~m} 2$. Sumber air ini berasal dari mata air alami yang terhindar dari cemaran. Kolam renang ini sudah mulai ramai dikunjungi terutama anak-anak dan pelajar. Di sekitar kolam renang sudah dibangun fasilitas pendukungnya. Pengelolaan kolam renang akan diserahkan pada kelompok-kelompok produktif dari masyarakat Polengan;

5. Potensi peternakan sapi. Hampir setiap petani khususnya di Gowok memiliki sapi 1 2 ekor. Beberapa petani bergabung membuat kandang kelompok. U mumnya, kotoran sapi digunakan sebagai pupuk kandang dengan proses fermentasi alami. Potensi kotoran sapi dengan volume yang tinggi dapat diarahkan menjadi Produsen Pupuk O rganik Padat (POP). U ntuk mendukung ke arah itu dapat diintroduksi teknologi fine compost sehingga proses pengomposan dapat dipercepat den gan hasil yang lebih 


\section{9}

berkualitas. Proses pengomposan dapat dijual sebagai materi belajar dan kelebihan produk dapat dijual ke luar desa;

6. Potensi industri kreatif terutama kuliner olahan pangan lokal yang telah berkembang, seperti Patilo dan Krupuk Ketela (lempeng) dapat ditingkatkan tampilan produknya sehingga lebih menarik dan nilai tawar dan jualnya meningkat;

7. Potensi pertanian lain yang dapat ditawarkan dan dijual yakni tanaman dalam pot (tabulampot) dengan wadah (pot) yang berbahan barang bekas/limbah rumah tangga. Pengembangan ini didukung oleh melimpahnya ketersediaan pupuk kandang yang dapat dijadikan campuran medium

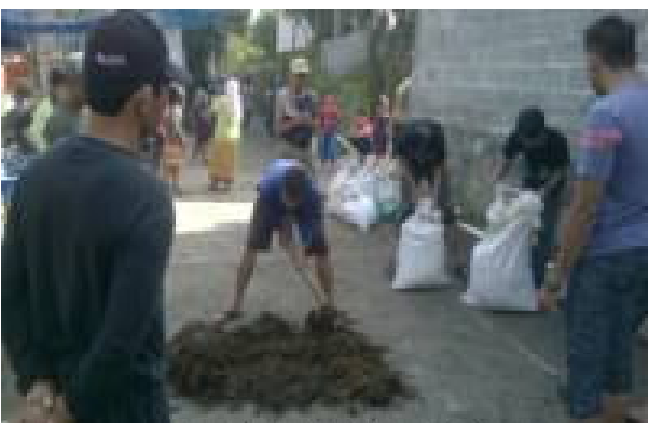

Gambar 1. Penyiapan bahan baku (kotoran sapi dan bahan lokal lain)

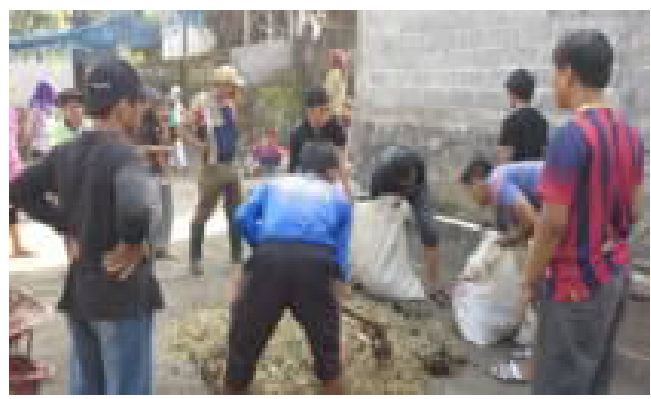

Gambar 2. Proses pengomposan tanam dalam pot. Komoditastanaman yang dapat dikembangkan yakni tanaman sayuran dan obat.

\section{Pelatihan dan Praktik Pembuatan Pupuk Organik}

\section{a. Pupuk Organik Padat (POP)}

Program ini bertujuan memberikan pemahaman dan ketrampilan kepada anggota kelompoktani ternak agar mau dan mampu mengolah kotoran ternak menjadi kompos dengan kualitas yang lebih baik dan memiliki nilai tawar dan jual yang lebih baik juga.

Pengolahan kompos dilakukan dengan proses fermentasi sederhana dengan bahanbahan yang mudah didapat secara lokal dengan teknologi fine compost.

Program ini dilaksanakan di D usun Gowok maupun Dusun Polengan. Kegiatan ini diikuti oleh 40 petani dari dua dusun, terutama yang memiliki ternak sendiri. $\mathrm{H}$ asilnya diapresiasi baik oleh semua petani, mengingat selama ini proses pengomposan yang dilakukan oleh petani tanpa masukan teknologi pengomposan (hanya alami). M enurut petani proses pengomposan lebih baik dan waktunya lebih cepat sehingga produknya (kompos) lebih baik.

\section{b. Pembuatan Pupuk Organik Cair}

Kegiatan ini bertujuan untuk pemanfaatan urin sapi yang volumenya banyak di setiap 


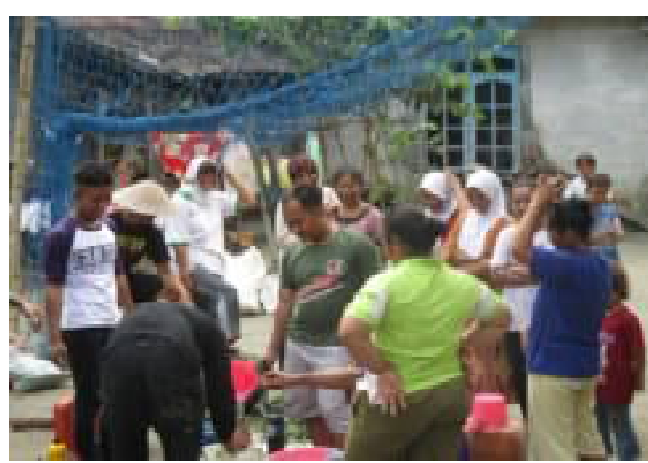

Gambar 3. Proses fermentasi bahan baku urin sapi

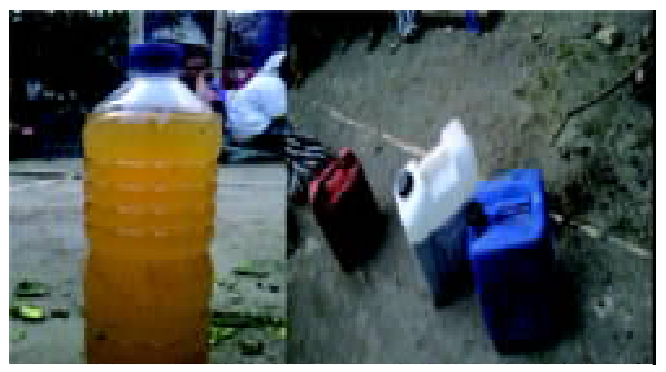

Gambar 4. Produk Pupuk Organik Cair berbahan baku urin sapi kandang sehingga tampak tidak higienis. O leh karena itu, perlu dilakukan upaya pemanfaatan urin sapi tersebut dengan cara diolah menjadi produk yang lebih manfaat dan bernilai ekonomis. Pelaksanaan kegiatan ini diikuti oleh kelompok tani pria dan kelompok tani wanita (KTW). Kegiatan ini dilaksanakan dengan bentuk pelatihan dan praktik pembuatan Pupuk Organik Cair (POC) di Dusun Gowok.

Proses pembuatan pupuk organik cair dilakukan dengan cara urin sapi ditampungke dalam ember kemudian dimasukkan dalam jerigen atau wadah lain yang tertutup. Selanjutnya, diberikan Bio-Starter yang berisi bakteri efektif pengurai agar proses fermentasi berjalan dengan baik dan cepat.

\section{c. Pengelolaan Sampah}

Keprihatinan akan peningkatan volume sampah rumah tangga dari hari ke hari memunculkan ide untuk melakukan pengelolaan agar tidak terjadi pencemaran lingkungan sehingga lingkungan sehat dan indah.

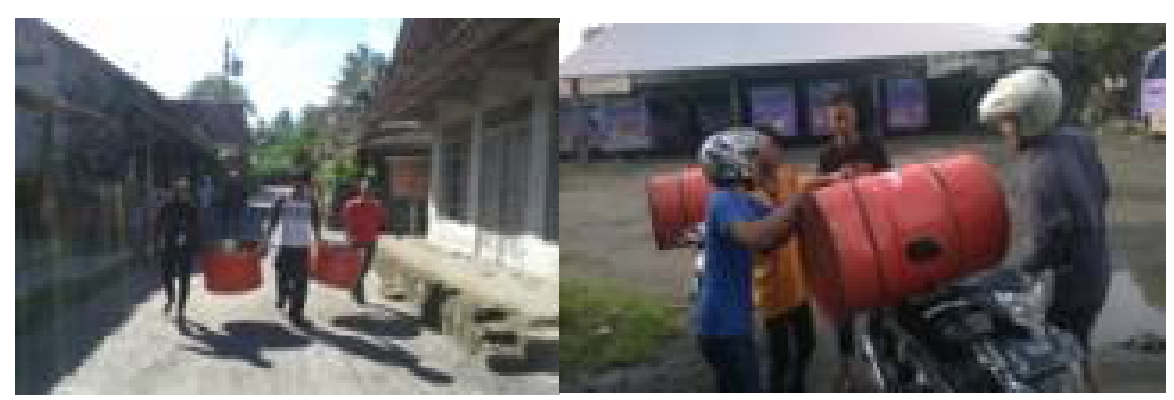

Gambar 5. Penyiapan tempat penampungan sampah

Pengelolaan sampah dilakukan secara mandiri (Kelola Sampah M andiri/ KSM) oleh tiap rumah tangga dengan cara memilah sampah sesuai kategorinya, yaitu organik dan non organik. Pemilahan menjadi dua kategori bersifat sementara dikarenakan pengelolaan sampah bagi masyarakat merupakan hal baru atau belum terbiasa. Namun, apabila 


\section{1}

pemilahan dengan dua kategori sudah menjadi kebiasaan maka selanjutnya perlu dikembangkan pemilahan dengan kategori sesuai bahan baku (seperti kertas, kaca, logam dan plastik). Oleh karena itu, dalam pemberdayaan ini diawali dengan penyiapan tempat penampungan sampah sementara (TPSS) bagi beberapa rumah tangga. TPSS disiapkan bersama masyarakat berupa tong

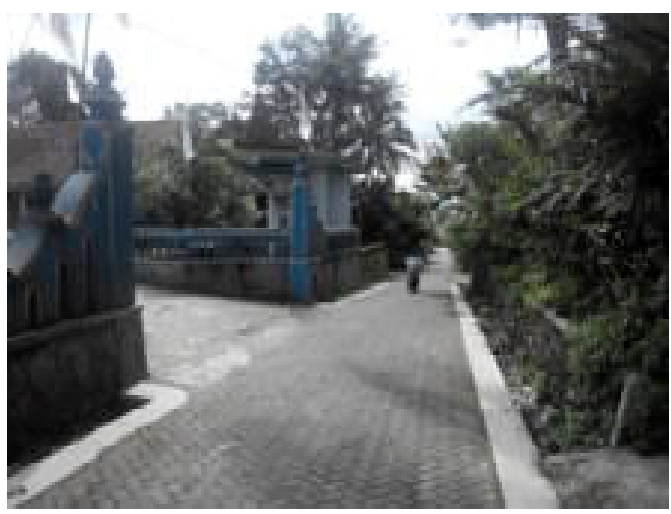

Gambar 6. Lingkungan Desa Polengan bekas tempat minyak tanah atau oli. Tong telah tersedia dipotong menjadi dua bagian, yaitu satu bagian untuk sampah organik dan satu bagian lainnya untuk sampah non organik.

Tujuan kegiatan ini dapat tercapai dengan bukti lingkungan desa tampak bersih dan nyaman. Sampah organic diarahkan agar dikelola lebih lanjut menjadi pupuk organik dengan cara seperti pada pembuatan pupuk organik (PO P) padat di atas.

\section{d. Perpustakaan D esa}

Sejalan dengan tema D esa Belajar, program ini bertujuan untuk meningkatkan minat baca masyarakat khususnya anak-anak. Lokasi desa yang cukup jauh dari pusat kota berdampak pada minimnya sarana baca khususya ketersediaan buku-buku bacaan selain buku pelajaran sekolah. Program ini dilakukan dengan membuat perpustakaan mini dan menyediakan beberapa buku bacaan untuk masyarakat, khususnya bahan bacaan anak-anak. Program ini direspon yang sangat baik khususnya kalangan anak-anak yang selama ini kurang mendapatkan fasilitas sarana baca yang memadai dari sekolah. Program perpustakaan mini dilaksanakan di D usun Gowok dengan pertimbangan berada di tengah-tengah desa sehingga memudahkan akses bagi masyarakat semua dusun.

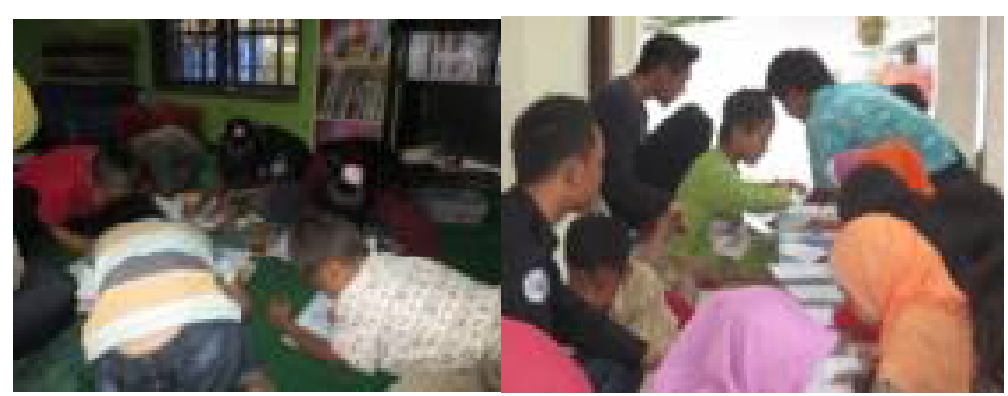

Gambar 7. Suasana perpustakaan mini 


\section{e. Belajar Alam dan Pertanian (vertikultur)}

Program ini ditujukan kepada anak-anak agar lebih mengenal dan menyukai pertanian. Program ini juga sekaligus bertujuan untuk uji coba salah satu paket yang bisa menjadi sajian dalam konsep D esa Belajar.

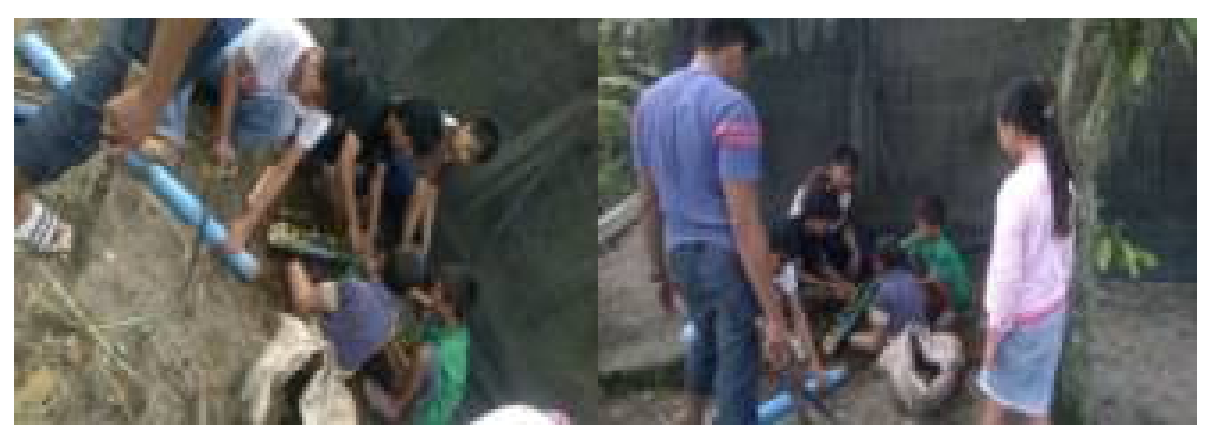

Gambar 8. Rancang bangun peralatan teknik vertikultur tanaman

Gambar 8 menunjukkan antusias anak-anak muda dalam kegiatan rancang bangun peralatan teknik vertikultur tanaman. Sistem vertikultur dipilih dengan tujuan membangun daya tarik dan pemahaman baru bagi masyarakat, terutama anak-anak terhadap pertanian. Tawaran teknologi baru tersebut sangat diapresiasi masyarakat dikarenakan selamaini yang dikenal dan dipahami oleh mereka yakni pertanian di lahan. Sistem ini diterapkan berbasis material lokal, seperti bambu bukan pralon, pupuk organik buatan sendiri, dan lainnya. Program ini telah berhasil menarik minat anak-anak karena mengetahui bahwa praktik pertanian dapat dilakukan di sekitar atau di halaman rumah.

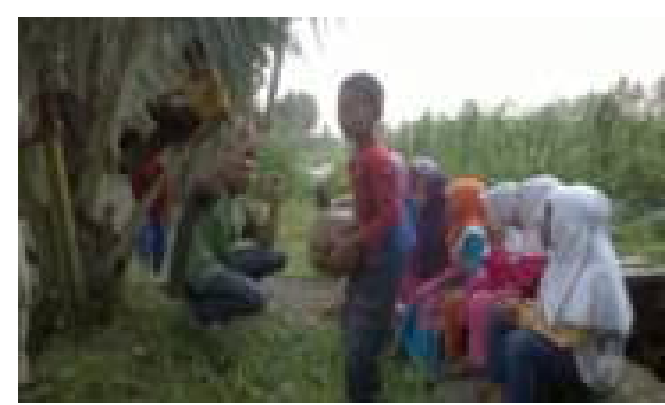

Gambar 8. Anak-anak sedang belajar alam sekitar

Anak-anak jugadipahamkan tentang alam sekitar baik ragam komponen penyusunnya maupun peran dan fungsinya. Belajar tentang alam sekitar sangat penting bagi anakanak dengan tujuan pengayaan pengetahuan alam yang telah diterima di sekolah. Tujuan lain yakni untuk memperkuat pembangunan keimanan sejak dini. Penyadaran akan kehadiran Sang Pencipta dengan manifestasi alam sekitar sebagai ciptaan-N ya mudah ditanmkan melalui medium alam. 


\section{SIM PULAN}

Semua program pemberdayaan masyarakat yang telah dilakukan di D esa Polengan, Kecamatan Srumbung, Kabupaten Magelang telah diapresiasi dengan baik oleh masyarakat. Inisiasi Desa Belajar Alam dan Pertanian dapat dicapai pada program pemberdayaan ini. Keberlanjutan pembangunan D esa Belajar Alam dan Pertanian diperlukan pendampingan intensif pada program pemberdayaan masyarakat lanjutan.

\section{UCAPAN TERIMA KASIH}

Program pemberdayaan masyarakat ini didukung sepenuhnya oleh Universitas M uhammadiyah Yogyakarta melalui Lembaga Penelitian, Publikasi dan Pengabdian M asyarakat dan Perangkat D esa serta masyarakat D esa Polengan, Srumbung, M agelang.

\section{DAFTAR PUSTAKA}

Blackstock, Kirstay. 2005. A critical look at community base tourism. Community

Development J ournal, 40/1 : 39 - 49

Daniel, M., Darmawati dan Nieldalina. 2008. PRA: Pendekatan Efektif Mendukung Penerapan Penyuluhan Partisipatif dalam U paya Percepatan Pembangunan Pertanian. Bumi Aksara, Jakarta. 155 hal.

Echtner, Charlotte M. 2002. The content of the third world tourism marketing

Approach. International J ournal of Tourism Research, 4 : 413-434

Gartner, William C. 2004. Rural tourism development in the USA.International

J ournal of Tourism Research, 6 : 151 - 164

Lansing, Paul dan Paul De Vries. 2007. Sustainable tourism : ethical alternative or marketing ploy? Journal of Business Ethics, 72:77-85
Pike, Steven. 2005. Tourism destination branding complexity. The Journal of Product and Brand Management, 14/4: 258 - 259 Samidjo, Gatot S. 2016. Kajian Spasial-Ekologi Varietas Padi pada Berbagai Ekosistem Sawah Irigasi dalam Rangka Pembangunan Pertanian Berkelanjutan. Disertasi Program Doktor IImu Lingkungan, Sekolah Pascasarjana UGM. Welford, Richard dan Bjarne Ytterhus.2004. Suistaneble development and tourism destination management : A case study of the Lillahammer region, Norwey.International J ournal of Sustainable Development and World Ecology, 11:410 422 